\title{
A New Oxygen Uptake Measurement Supporting Target Selection for Endobronchial Valve Treatment
}

\author{
Jorrit B.A. Welling a, ${ }^{a}$ Karin Klooster ${ }^{a, b}$ Jean-Paul Charbonnier ${ }^{c}$ \\ Eva M. Van Rikxoort ${ }^{c}$ Clemens R.M. Barends ${ }^{d}$ Huib A.M. Kerstjens ${ }^{a, b}$ \\ Nick H.T. Ten Hacken ${ }^{a}$ b Jorine E. Hartman ${ }^{a, b}$ Dirk-Jan Slebos ${ }^{a, b}$ \\ a Department of Pulmonary Diseases, University Medical Center Groningen, University of Groningen, \\ Groningen, The Netherlands; ${ }^{\mathrm{b}}$ Groningen Research Institute for Asthma and COPD, University Medical Center \\ Groningen, University of Groningen, Groningen, The Netherlands; ' $T$ Thirona, Nijmegen, The Netherlands; \\ dDepartment of Anesthesiology, University Medical Center Groningen, University of Groningen, \\ Groningen, The Netherlands
}

\section{Keywords}

Bronchoscopic lung volume reduction - Endobronchial valves · Perfusion · Oxygen uptake · Emphysema

\section{Abstract}

Background: Adequate target lobe selection for endobronchial valve (EBV) treatment in patients with severe emphysema is essential for treatment success and can be based on emphysema destruction, lobar perfusion, lobar volume, and collateral ventilation. As some patients have $>1$ target lobe for EBV treatment, we were interested whether we could identify the least functional lobe. Objectives: The objective of this study was to investigate the relationship between endoscopic lobar measurement of oxygen uptake, lobar destruction, and vascular volume, and whether this could help in identifying the least functional lobe and thus optimal target for EBV treatment. Method: We prospectively included patients who were scheduled for EBV treatment in our hospital. A customized gas analysis setup was used to measure lobar $\mathrm{O}_{2}$ uptake after lobar balloon occlusion. Quantitative $\mathrm{CT}$ analysis was performed to assess the degree of emphysematous destruction and lobar arterial and venous volumes.
Results: Twenty-one (5 male/16 female) patients with emphysema (median age 63 years, $\mathrm{FEV}_{1} 25 \%$ of predicted, residual volume $234 \%$ of predicted) were included, and 49 endoscopic lobar measurements were performed. A lower $\mathrm{O}_{2}$ uptake significantly correlated with a higher degree of emphysematous lobar destruction (Spearman's $p: 0.39, p<$ 0.01 ), and lower arterial and venous vascular volumes of the lobes $(-0.46$ and -0.47 , respectively; both $p<0.001)$. Conclusions: Endoscopic measurement of lobar $\mathrm{O}_{2}$ uptake is feasible in patients with emphysema. Measurement of lobar $\mathrm{O}_{2}$ uptake helped to identify the least functional lobe and can be used as additional tool for EBV target lobe selection.

(c) 2019 The Author(s)

Published by S. Karger AG, Basel

\section{Introduction}

Endobronchial valve (EBV) treatment is a minor invasive and effective bronchoscopic lung volume reduction treatment in selected patients with severe emphysema [1-4]. The purpose of EBV treatment is to induce lobar atelectasis by occluding all segmental bronchi of a destructed and hyperinflated lobe with one-way valves

\begin{tabular}{ll}
\hline KARGER & $\begin{array}{l}\text { (c) } 2019 \text { The Author(s) } \\
\text { Published by S. Karger AG, Basel }\end{array}$ \\
E-Mail karger@karger.com & $\begin{array}{l}\text { This article is licensed under the Creative Commons Attribution- } \\
\text { NonCommercial-NoDerivatives 4.0 International License (CC BY- } \\
\text { NC-ND) (http://www.karger.com/Services/OpenAccessLicense). } \\
\text { Usage and distribution for commercial purposes as well as any dis- } \\
\text { tribution of modified material requires written permission. }\end{array}$
\end{tabular}

Jorrit B.A. Welling, MD

Department of Pulmonary Diseases AA11

University Medical Center Groningen

PO Box 30001, NL-9700 RB Groningen (The Netherlands)

E-Mail j.b.a.welling@umcg.nl 
Fig. 1. Schematic representation of the measurement setup demonstrating occlusion of the left upper lobe.

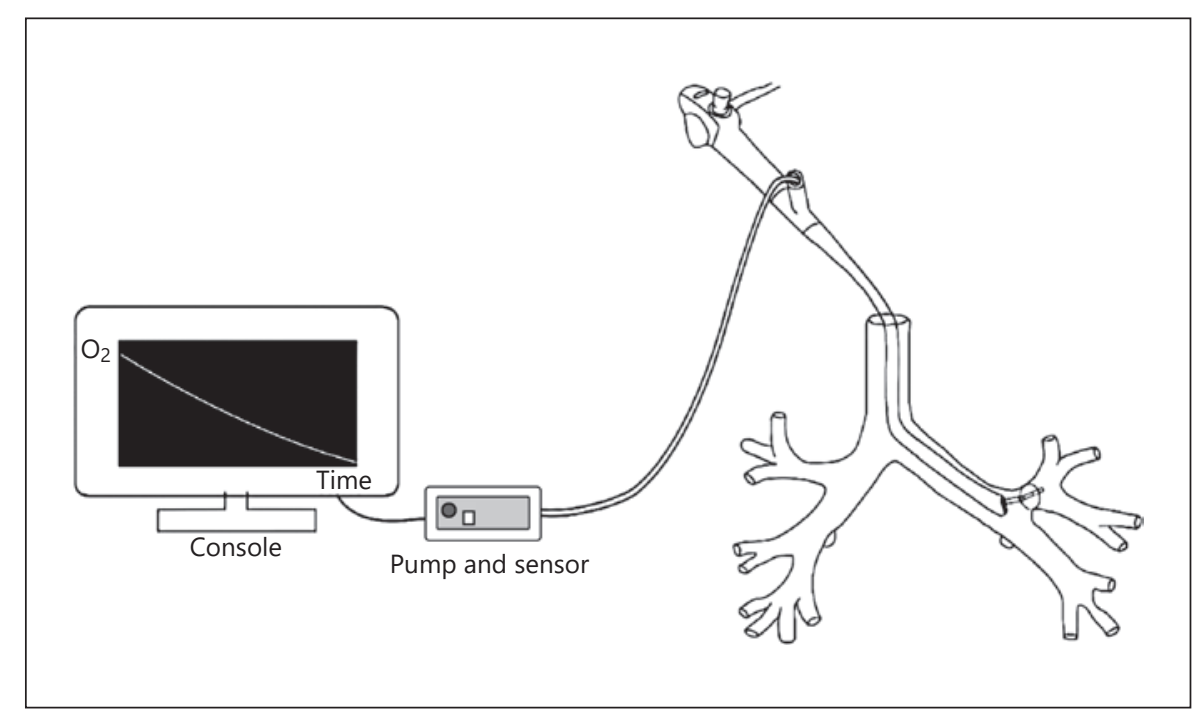

[5]. Patient selection is essential for EBV treatment success, and important selection criteria are the presence of a suitable emphysematous target lobe with absence of collateral ventilation $(\mathrm{CV})$, the degree of lung hyperinflation, and absence of significant comorbidity [5]. Target lobe selection is based on the degree of emphysema destruction, absence of CV, lobar volume of the target and ipsilateral lobe, low lobar perfusion assessed using perfusion scintigraphy, and absence of pleural adhesions [68].

Some patients have $>1$ suitable target lobe for EBV treatment. Quantitative CT ( $\mathrm{qCT}$ ) analysis may help to identify the most suitable target lobe for treatment. In addition to qCT analysis, perfusion scintigraphy may also help to identify the target lobe in these patients, preferably targeting the lobe with the lowest perfusion [9]. However, in our hospital, we encounter patients who still have $>1$ target lobe eligible for EBV treatment after applying all available diagnostic techniques.

Freitag et al. [10] previously demonstrated the use of endoscopic capnometry and oximetry curves to improve EBV target zone identification. Building on this approach, we wanted to investigate whether the quantification of lobar oxygen $\left(\mathrm{O}_{2}\right)$ uptake capacity might help identifying the least functional lobe and, therefore, best target lobe for EBV treatment.

The objective of this study was to investigate the relationship between endoscopic lobar measurement of oxygen uptake, lobar destruction, and vascular volume, and whether this could help in identifying the least functional lobe and thus optimal target for EBV treatment.

\section{Methods}

\section{Study Design}

In this prospective feasibility study, we included patients with severe emphysema who were scheduled in a national treatment registry (BREATH-NL: NCT02815683) for EBV treatment in our hospital from February 2018 to May 2018. All patients provided written informed consent for the treatment procedure, flow measurements, and data collection.

\section{Outcomes}

The primary outcome of this study was the association between the degree of lobar emphysematous destruction and $\mathrm{O}_{2}$ uptake capacity.

Secondary, we wanted to investigate the association of the uptake capacity of $\mathrm{O}_{2}$ in the measured lobes with vascular qCT parameters: arterial and venous lobe volumes. Furthermore, the association between lobar emphysematous destruction and arterial and venous lobe volumes was assessed.

\section{Equipment}

Endoscopic $\mathrm{O}_{2}$ concentration measurements were performed using a customized setup. An ISA ${ }^{\circledR}$ sidestream gas analyzer (Masimo AB, Danderyd, Sweden) was used, sampling air at $50 \mathrm{~mL}$ per minute and collecting data 20 times per second [10]. To achieve lobar isolation, a Chartis ${ }^{\circledR}$ catheter (Pulmonx Inc., Redwood City, CA, USA) was used. The Chartis catheter is equipped with an inflatable balloon tip and can be advanced through the working channel of a flexible bronchoscope [6]. A Nomoline ${ }^{\circledR}$ sampling line $(200 \mathrm{~cm}$; Masimo $\mathrm{AB})$ was used to prevent moisture from disturbing the gas measurements. The sampling delay caused by the length of the Chartis catheter and Nomoline was approximately 2 s. A Tangent ${ }^{\circledR}$ console (Burlingame, USA) running customized software (Pulmonx Inc., Redwood City, CA, USA) was used to allow characterization and live visualization of data during the measurements, as well as data extraction after the procedure. An overview of the measurement setup can be found in Figure 1. 


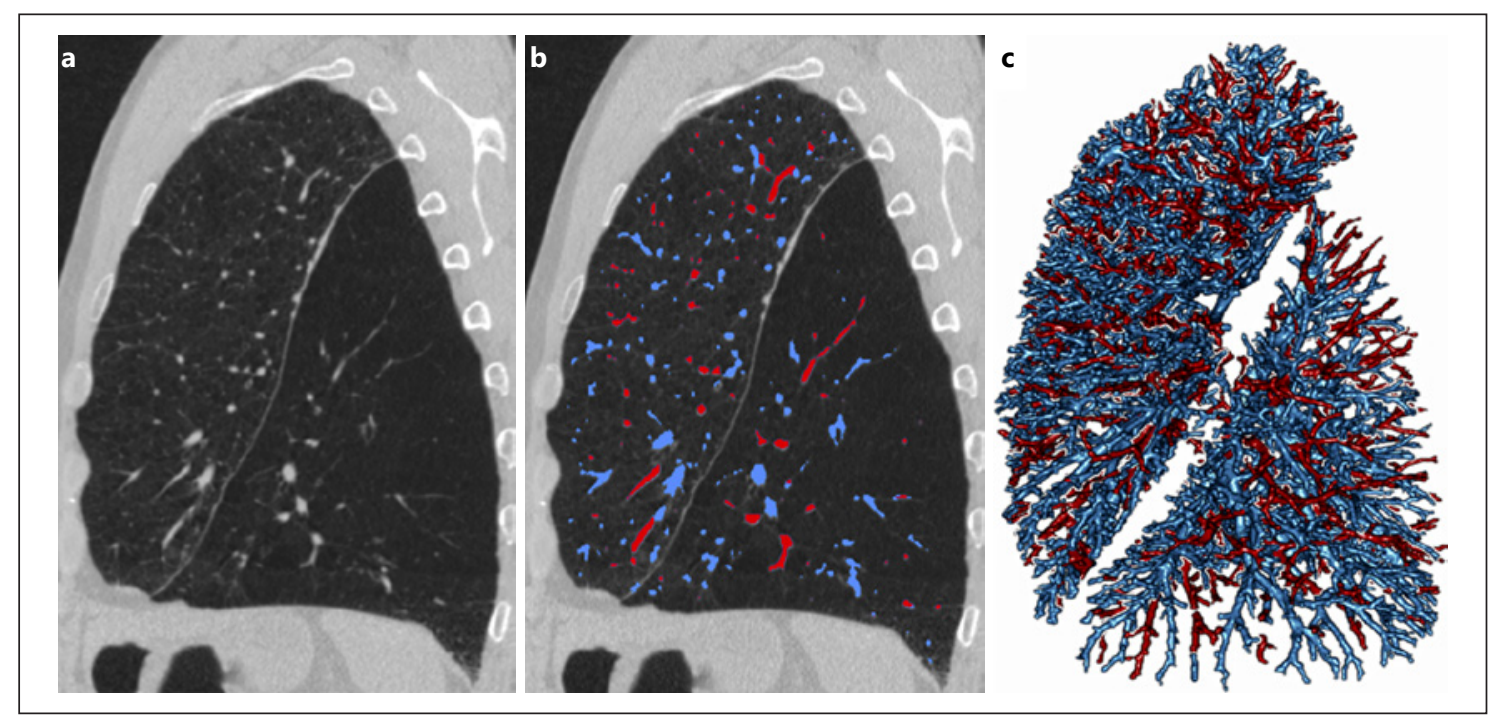

Fig. 2. Quantitative CT analysis of arterial and venous volumes. a Sagittal view of the left lung with left lower lobe predominant emphysema. b 2D artery-vein overlay of the left lung with decreased vascular volume in the left lower lobe. c 3D artery-vein rendering of the left lung.

\section{Measurement}

The presence of interlobar CV was assessed in every patient using the Chartis measurement. After the Chartis measurement, the entrance of the lobe selected for measurement was occluded by inflating the balloon of the Chartis catheter again, effectively isolating this lobe for $2 \mathrm{~min}$. Directly after occlusion, $\mathrm{O}_{2}$ uptake measurement was started by measuring the oxygen concentration distal of the inflated balloon. Measurements were performed at least in the EBV treatment target lobe as well as the adjacent lobe. The right middle lobe was excluded from measurement.

Measurements were only included for analysis when CV absence was confirmed by Chartis, and a reliable gas concentration signal was obtained. Measurements were excluded from analysis when total airway collapse occurred, when mucus occluded the catheter distorting the measurements, or when the balloon occlusion of the airway was lost during measurement.

Measurements (as well as Chartis and the EBV procedure) were performed under general anesthesia. Patients were intubated with a flexible 9-mm endotracheal tube. The primary ventilator settings were: volume-controlled ventilation mode with target settings of low ventilation frequency (8-10 times/min), tidal volumes 4-6 $\mathrm{mL} / \mathrm{kg}$, fixed fraction of inspired oxygen $\left(\mathrm{FiO}_{2}\right)$ of $50 \%$, long expiratory settings (inspiratory/expiratory ratio of 1:3-1:4), and positive end-expiratory pressure of $3 \mathrm{~cm} \mathrm{H}_{2} \mathrm{O}$.

qCT Analysis

Lobar emphysematous destruction and lobar volumes were determined using the Strat $\mathrm{X}^{\circledR} \mathrm{qCT}$ platform (Pulmonx Inc). The assessment of the arterial and venous volume per lobe was performed using Thirona lung quantification software (Thirona, Nijmegen, the Netherlands; Fig. 2).

Statistical Analysis

Linear regression was performed to quantify $\mathrm{O}_{2}$ uptake capacity with $\mathrm{O}_{2}$ concentration as a dependent variable and measurement duration as independent variable. Slope coefficients were derived of $\mathrm{O}_{2}$ uptake capacity (change in $\% \mathrm{O}_{2} / \mathrm{s}$ ) for each measurement.

Spearman's $\rho$ was used to test the association between $\mathrm{O}_{2}$ uptake capacity and lobar emphysematous destruction (\% voxels <-950 Hounsfield units), the association between $\mathrm{O}_{2}$ uptake capacity and arterial or venous volume in the measured lobes, the association between arterial and venous volumes and lobar emphysematous destruction, and the association between $\mathrm{O}_{2}$ uptake capacity and lobar volume. $p$ values $<0.05$ were considered significant. Statistical analyses were performed using SPSS version 23 (IBM, New York, NY, USA).

\section{Results}

\section{Patients}

Twenty-one patients were included with a median age of 63 years (range 39-73), 24\% male, and a forced expiratory volume in $1 \mathrm{~s}\left(\mathrm{FEV}_{1}\right)$ of $25 \%$ of predicted (range $13-$ 39). Patient characteristics can be found in Table 1.

\section{$\mathrm{O}_{2}$ Uptake Measurements}

We performed $\mathrm{O}_{2}$ uptake measurements in 69 different lobes, and of these we included 49 in our analysis (Table 2). Measurements were performed in the right upper lobe $(n=9)$, right lower lobe $(n=7)$, left upper lobe $(n=$ $17)$, and the left lower lobe $(n=16)$. Twenty of 69 measurements (29\%) were excluded from analyses because of the following reasons: interlobar CV was present $(n=8)$, no full airway seal was achieved with the balloon or this seal was lost during measurement $(n=5)$, severe airway 
collapse occurred ( $n=3)$, no flow state was encountered $(n=1)$, and unspecified measurement failure $(n=3)$.

The average $\mathrm{O}_{2}$ uptake was $0.13 \pm 0.06 \% \mathrm{O}_{2}$ decrease per second, indicating an average decrease of $50 \% \mathrm{FiO}_{2}$ to $34.4 \%$ during a 2 -min measurement.

A higher degree of lobar emphysematous destruction was significantly associated with a lower $\mathrm{O}_{2}$ uptake (Spearman's $\rho: 0.39, p<0.01$ ). Furthermore, lower arterial and venous volumes on qCT of the measured lobes were significantly correlated with lower $\mathrm{O}_{2}$ uptake ( $\rho$ : -0.46 and -0.47 , respectively, both $p<0.001$ ). Lower arterial and venous volumes of the lobes were significantly associated with higher lobar emphysematous destruction (both $\rho-0.60, p<0.001$ ). No significant association was found between lobar volume and $\mathrm{O}_{2}$ uptake capacity ( $\rho$ : $-0.13, p=0.37)$. Scatterplots can be found in Figure 3 .

\section{Discussion}

In this study, we investigated a functional endoscopic approach to EBV target lobe selection: selective lobar measurement of $\mathrm{O}_{2}$ uptake capacity. A lower $\mathrm{O}_{2}$ uptake was significantly correlated with higher lobar emphysematous destruction and lower arterial and venous vascular volumes of the target lobes.

To our knowledge, this is the first study describing endoscopic lobar $\mathrm{O}_{2}$ uptake measurement to improve EBV target selection in patients with severe emphysema. Freitag et al. [10] previously demonstrated target zone identification guided by endoscopic capnometry and oximetry curves using a similar measurement setup and were able to improve target zone identification using this technique, but this approach did not allow for quantification of lobar uptake capacity. Adequate target lobe selection for EBV treatment is critical since complete occlusion of a lobe with a relatively high uptake capacity for $\mathrm{O}_{2}$ can lead to respiratory insufficiency instead of the targeted treatment benefit for the patient.

Oxygen uptake in a lobe can be influenced by several factors. First of all, oxygen uptake is dependent of the amount of local perfusion. In this study, qCT analysis was performed to assess arterial and venous volumes in the target lobes, serving as a surrogate measure of local perfusion. In future studies, the comparison of single photon emission CT outcomes to endoscopic lobar $\mathrm{O}_{2}$ uptake capacity could be of additional value. Second, $\mathrm{O}_{2}$ uptake capacity depends on the integrity of local lung tissue and alveoli in the target lobes, which is why we related our endoscopic $\mathrm{O}_{2}$ uptake measurements to $\mathrm{qCT}$ analysis of
Table 1. Patient characteristics $(n=21)$

\begin{tabular}{lc}
\hline Females/males, \% & $76 / 24$ \\
Age, years & $63(39-73)$ \\
BMI, kg/m ${ }^{2}$ & $23(19-35)$ \\
Pack-years & $40(9-147)$ \\
FEV $_{1}, \%$ of predicted & $25(13-39)$ \\
RV, \% of predicted & $234(175-327)$ \\
TLC, \% of predicted & $141(111-170)$ \\
RV/TLC ratio & $0.7(0.5-0.8)$ \\
DLCO, mmol/min $\times \mathrm{kPa}$ & $2.0(1.4-4.0)$ \\
DLCO, \% of predicted & $27(19-40)$ \\
6MWD, m & $287(111-479)$ \\
SGRQ total score, units & $61(40-82)$ \\
\hline
\end{tabular}

Data are presented as medians (ranges. BMI, body mass index; $\mathrm{FEV}_{1}$, forced expiratory volume in $1 \mathrm{~s}$; RV, residual volume; TLC, total lung capacity; DLCO, diffusion capacity for carbon dioxide; 6MWD, 6-min walking distance; SGRQ, St. George's Respiratory Questionnaire.

Table 2. Gas and quantitative CT measurements $(n=49)$

Oxygen uptake, $\% \mathrm{O}_{2} / \mathrm{s}$
Measurement duration, $\mathrm{s}$
Emphysematous destruction in the
measured lobe, voxels <-950 HU
Lobar volume, $\mathrm{mL}$
Lobar vascular volume, $\mathrm{mL}$
Lobar arterial volume, $\%$
Lobar venous volume, $\%$

$-0.11(-0.31$ to -0.01$)$
$124(63$ to 304$)$
$40(5$ to 60$)$
$1,574(912$ to 3,009$)$
$101(59$ to 165$)$
$3.9(2.5$ to 6.0$)$
$2.6(1.5$ to 4.0$)$

Data are presented as medians (ranges). HU, Hounsfield units.

emphysematous destruction in this study. A third factor that could influence local $\mathrm{O}_{2}$ uptake is variance in cardiac output, which was not assessed during the procedure in our study [11]. A fourth factor is the time between deflation of the Chartis balloon after CV measurement and the re-inflation of this balloon for oxygen uptake measurement. Considering the minimum amount of 1 min needed to convert to oxygen uptake measurement after CV measurement, our ventilation settings, and knowing that a median air volume of $390 \mathrm{~mL}$ is expired during Chartis measurement in $\mathrm{CV}$-negative lobes, we do not believe that this factor played a significant role in this study [12]. A last factor is the alveolar-arterial pressure gradient of oxygen, which depends on $\mathrm{FiO}_{2}$ [11]. For standardization reasons, we ventilated all our patients with an $\mathrm{FiO}_{2}$ of $50 \%$, using the same ventilator settings, avoiding high peak pressures of ventilation.

This study has several limitations. All measurements were performed while patients were on positive pressure ventilation during general anesthesia, which could have 

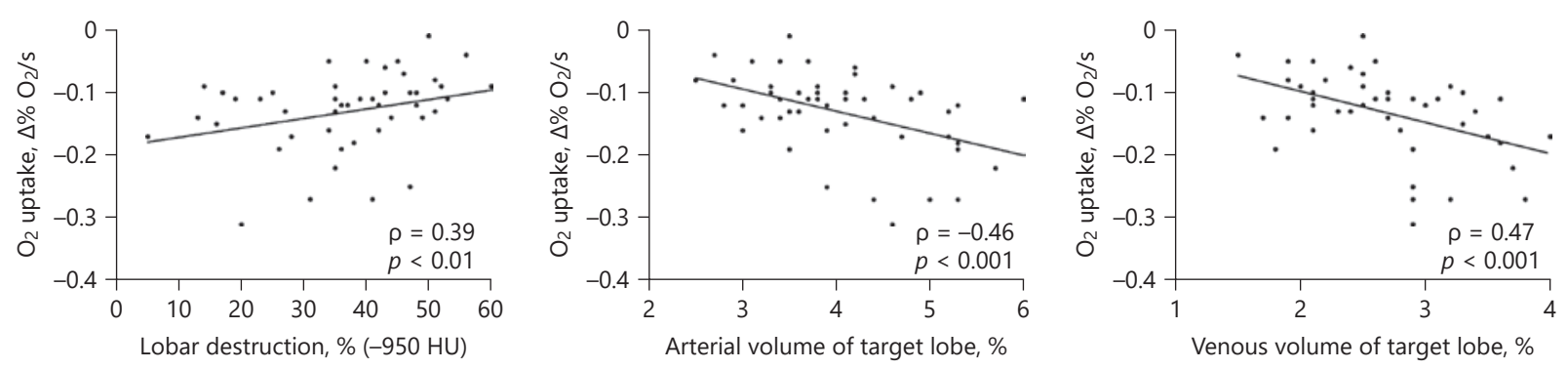

Fig. 3. Scatterplots of oxygen uptake capacity versus lobar destruction, and arterial and venous volumes of the target lobes.

affected measurement outcomes when compared to spontaneously breathing patients, but in clinical practice it is recommended to perform both the Chartis measurement as well as the EBV procedure under general anesthesia [12]. In all patients, a supranormal standardized $\mathrm{FiO}_{2}$ of $50 \%$ was maintained during the procedure in order to magnify the $\mathrm{O}_{2}$ slope signal. The measurements were performed during an arbitrary 2-min interval, and, to assess $\mathrm{O}_{2}$ uptake, linear regression was performed to calculate slope coefficients. During an extended measurement, the $\mathrm{O}_{2}$ uptake pattern that now exhibited linear relationship properties would possibly have exhibited exponential function properties. Our measurement setup had a measurement delay of $2 \mathrm{~s}$ due to catheter length; in future research, other measurement techniques such as optical fiber probes could perhaps be used to achieve gas concentration measurements with less delay [13].

Lobes that were diagnosed as $\mathrm{CV}$ positive by Chartis measurement were excluded from our analysis as the supply of oxygen through interlobar collateral channels could disturb oxygen uptake measurements in the isolated lobes. One might even elaborate on the possibility of this being an alternative to the current measurement of $\mathrm{CV}$ using flow instead of gas components.

In our experience, the measurements were feasible, easy to perform, and provided information that was of additional value in target lobe selection for EBV treatment. Future developments in this field could include the development of a console displaying the live $\mathrm{O}_{2}$ consumption rate during bronchoscopy.

In conclusion, endoscopic measurement of lobar $\mathrm{O}_{2}$ uptake is feasible in patients with emphysema. This new functional endoscopic approach to measure $\mathrm{O}_{2}$ uptake capacity at a lobar level can serve as an additional diagnostic tool to improve identification of a treatment target for lung volume reduction treatment with endobronchial valves, but more research is needed to validate this approach.

Endoscopic Measurement of Lobar $\mathrm{O}_{2}$ Uptake

\section{Acknowledgments}

We would like to thank the endoscopy nurses who assisted during the procedures and Judith Hartman for drawing Figure 1.

\section{Statement of Ethics}

We included patients with severe emphysema who were scheduled for EBV treatment in a national treatment registry (BREATHNL: NCT02815683). All patients provided written informed consent for the treatment procedure, flow measurements, and data collection.

\section{Disclosure Statement}

J.B.A.W., K.K., C.R.M.B., H.A.M.K., N.H.T.T.H. and J.E.H. have no conflicts of interest to disclose. E.M.R. is co-founder and shareholder of Thirona. J.-P.C. is shareholder of Thirona. D.-J.S. is a physician advisor and investigator for Pulmonx Inc.

\section{Funding Sources}

The Junior Scientific Masterclass, University of Groningen, provided financial support for the research position of J.B.A.W. This study was part of the SOLVE project, funded by the Dutch Lung Foundation (Longfonds; No. 5.1.17.171). Pulmonx Inc. provided the measurement device but was not involved in any other stage of this trial or manuscript preparation.

\section{Author Contributions}

J.B.A.W., K.K., N.H.T.T.H., J.E.H., and D.-J.S. undertook conception and design. J.B.A.W., D.-J.S., N.H.T.T.H., and K.K. performed all measurements and treatments. qCT analysis was performed by J.-P.C. and E.M.R.; J.B.A.W., K.K., J.E.H., and D.-J.S. acquired data. J.B.A.W., H.A.M.K., J.E.H., and D.-J.S. performed analysis and interpretation. All authors have read, improved, and approved the final manuscript. 


\section{References}

1 Klooster K, ten Hacken NH, Hartman JE, Kerstjens HA, van Rikxoort EM, Slebos DJ. Endobronchial Valves for Emphysema without Interlobar Collateral Ventilation. N Engl J Med. 2015 Dec;373(24):2325-35.

2 Valipour A, Slebos DJ, Herth F, Darwiche $\mathrm{K}$, Wagner M, Ficker JH, et al.; IMPACT Study Team. Endobronchial Valve Therapy in Patients with Homogeneous Emphysema. Results from the IMPACT Study. Am J Respir Crit Care Med. 2016 Nov; 194(9): 1073-82.

3 Kemp SV, Slebos DJ, Kirk A, Kornaszewska M, Carron K, Ek L, et al.; TRANSFORM Study Team *. A Multicenter Randomized Controlled Trial of Zephyr Endobronchial Valve Treatment in Heterogeneous Emphysema (TRANSFORM). Am J Respir Crit Care Med. 2017 Dec;196(12):1535-43.

4 Criner GJ, Sue R, Wright S, Dransfield M, Rivas-Perez $\mathrm{H}$, Wiese T, et al.; LIBERATE Study Group. A Multicenter Randomized Controlled Trial of Zephyr Endobronchial Valve Treatment in Heterogeneous Emphysema (LIBERATE). Am J Respir Crit Care Med. 2018 Nov;198(9):1151-64.
5 Herth FJ, Slebos DJ, Criner GJ, Valipour A, Sciurba F, Shah PL. Endoscopic Lung Volume Reduction: An Expert Panel Recommendation - Update 2019. Respiration. 2019;97(6): 548-57.

6 Mantri S, Macaraeg C, Shetty S, Aljuri N, Freitag L, Herth F, et al. Technical advances: measurement of collateral flow in the lung with a dedicated endobronchial catheter system. J Bronchology Interv Pulmonol. 2009 Apr;16(2):141-4.

7 Thomsen C, Theilig D, Herzog D, Poellinger A, Doellinger F, Schreiter N, et al. Lung perfusion and emphysema distribution affect the outcome of endobronchial valve therapy. Int J Chron Obstruct Pulmon Dis. 2016 Jun;11: 1245-59.

8 Welling JB, Hartman JE, van Rikxoort EM, Ten Hacken NH, Kerstjens HA, Klooster K, et al. Minimal important difference of target lobar volume reduction after endobronchial valve treatment for emphysema. Respirology. 2018 Mar;23(3):306-10.
9 Slebos DJ, Shah PL, Herth FJ, Valipour A. Endobronchial Valves for Endoscopic Lung Volume Reduction: Best Practice Recommendations from Expert Panel on Endoscopic Lung Volume Reduction. Respiration. 2017;93(2): $138-50$.

10 Freitag L, Lenkens D, Zarogoulidis P, KarpfWissel R, Hang H, Darwiche K. Functional bronchoscopy: development of a new bronchoscopic method for real-time gas exchange assessment of lobes and lung segments. Respiration. 2014;88(6):469-77.

11 Dunn JO, Mythen M, Grocott M. Physiology of oxygen transport. BJA Educ. 2016;16(10): 341-8.

12 Welling JB, Hartman JE, Ten Hacken NH, Franz I, Charbonnier JP, van Rikxoort EM, et al. Chartis Measurement of Collateral Ventilation: Conscious Sedation versus General Anesthesia - A Retrospective Comparison. Respiration. 2018;96(5):480-7.

13 Katagiri T, Shibayama K, Iida T, Matsuura Y. Infrared Hollow Optical Fiber Probe for Localized Carbon Dioxide Measurement in Respiratory Tracts. Sensors (Basel). 2018 Mar; 18(4):995. 